\title{
Business Cycle Dynamics of Economic Growth in the OECD Countries: Evidence from Markov-Switching Model
}

\author{
TARLOK SINGH \\ Griffith University, Australia*
}

\begin{abstract}
This study estimates the Markov-switching model and examines the business cycle dynamics of economic growth for a comprehensive set of eight OECD countries. The estimated duration of regime one (lower regime) is (i) shorter for Denmark, Sweden and Switzerland, (ii) moderate for France, and (iii) longer for Belgium, Spain and the U.S. The persistence of regime two (upper regime) is estimated to be (i) shorter for Belgium, Canada, Spain, Sweden and the U.S., (ii) moderate for Denmark and France, and (iii) longer for Switzerland. The stylized evidence for the persistence of a given state has important implications for the Keynesian policy activism and the formulation of macroeconomic stabilisation policies. The monetary and fiscal policies are used to reduce the amplitudes and time-durations of economic growth cycles and, thus, stabilise the output around its long-run natural rate level and the inflation around its target level. The short-run downward rigidities in prices in the goods markets and in nominal wages in the factor (labour) market tend to impinge upon the clearance of goods and factor markets and the acceleration of economic growth during recessions, thereby leading to the pathologically longer durations of lower regimes. While the longer durations of upper regimes support the use of expansionary economic policies, adequate precautions need to be taken for the inflationary implications of these policies.
\end{abstract}

Keywords: Business cycle, Economic growth, Probability, Markov-switching, Maximumlikelihood.

JEL Classifications: C20, C30, C32, E30, O40

\section{Introduction}

An analysis of the cyclical states and business cycle dynamics of aggregate output and economic growth remains central to the Keynesian and monetarist business cycle models. A

\footnotetext{
* Department of Accounting, Finance and Economics, Griffith Business School, Griffith University, Nathan Campus, 170 Kessels Road, Brisbane, Queensland-4111, Australia. Telephone: 61-7-37357796, Fax: 61-7-37353719, Email address: Tarlok.Singh@griffith.edu.au. I am grateful to the anonymous Referee of the journal for very useful comments and suggestions. I am, however, solely responsible for any errors and omissions that may remain in the paper.

(C) 2016 Tarlok Singh. Licensed under the Creative Commons Attribution - Noncommercial 3.0 Licence (http://creativecommons.org/licenses/by-nc/3.0/. Available at http: //rofea.org.
} 
number of factors could be catalytic to the switches in states, such as the (i) expansion and contraction in the components of aggregate demand (Keynesian models), (ii) anticipated and unanticipated expectational shocks to and the upward and downward 'plucks' in the growth of money supply ('plucking model'; Friedman, 1964, 1993), (iii) idiosyncratic shocks to productivity and aggregate supply (real business cycle models), and (iv) switches in the stance of macroeconomic policies. The adjustment process underlying the switches in states could be characterised by asymmetric dynamics that could arise from several factors including the Keynesian short-run rigidities in nominal wages and prices and the hysteresis of unemployment (Blanchard and Summers, 1986). The switches in states and the asymmetrical propagations of economic activity alter the dynamics of a linear autoregressive (AR) process and scuttle the temporal stability of the conventional ARMA and ARIMA models couched in the Box-Jenkins setting (Box and Jenkins, 1970). The Gaussian linear models with timeinvariant parameters and symmetry restrictions on economic fluctuations do not seem appropriate, and instead the nonlinear models are required to model the cyclical states of a given sequence. The work on the regime-switching models was pioneered by Quandt (1958) and Goldfeld and Quandt (1972, 1973). Tong and Lim (1980) and Tong (1983) pioneered the development of threshold autoregressive (TAR) model, which represents a univariate counterpart of the regime-switching model of Quandt (1958) and Goldfeld and Quandt (1972, 1973). When the delay determining the threshold is proxied by a lagged endogenous variable, then the AR process becomes self-exciting and the TAR model is described as the selfexciting threshold autoregressive (SETAR) model. The SETAR model assumes a fast speed of adjustment and determines the discrete switches in economic states. A generalized rendition of the non-smooth SETAR model is the smooth transition autoregressive (STAR) model that allows for the varying degrees of speed of adjustment across regimes (Terasvirta and Anderson, 1992; Granger and Terasvirta, 1993; Terasvirta, 1994).

Both SETAR and STAR models assume that the switches in regimes are predictable and directly observable. Hamilton $(1989,1994)$ develops a variant of the Markov-switching (MS) model of Goldfeld and Quandt (1973), and instead assumes that the switches in regimes are unobservable and are determined by a stochastic and latent variable. The regime-switches, therefore, are not known with certainty. The stochastic process underlying the evolution of a given sequence switches across states according to a first-order latent Markov-chain. The Markov-switching model is similar to the SETAR and STAR models in that the regimeswitching is not identified under the null hypothesis of linearity. The implications of Markovswitching model are, however, quite different from those of the SETAR and STAR models. The probability of switch is a function of the threshold variable in SETAR model and the transition variable in STAR model (van Dijk et al, 2002). The regime-switching is 


\section{SINGH Business Cycle Dynamics}

endogenous and is generated by fixed AR lags in these models. In contrast, the probability of changing regimes in Markov-switching model, at any given time, is only a function of the state of business cycle and is constant over time. The regime-switching is exogenous and is generated by an unobserved and latent Markov-chain.

The delayed economic signals regarding the state of the economy and the policy dilemmas and resultant lagged policy responses to economic states tend to accentuate the mild slowdowns into the great recessions and the modest recoveries into the booms. The temporal profile of output tends to be characterised by the classical two-states of expansions and recessions. The intermediate states of mild downturns and modest recoveries could be resolved through the 'invisible hand' of the market forces of demand and supply with possibly no or little need for policy interventions. The discernible and persistent deviations of the output from its natural rate level and the inflation from its target level are the key conditioning factors that necessitate the need for fiscal policy responses and determine the policy reaction functions of the central banks. The classical business cycles reflect the absolute changes in output and are fundamentally different from the growth cycles; see Zarnowitz $(1985,1991)$ and Stadler (1994) for the surveys. The cyclical states of unusually low (troughs) and high (peaks) economic growth and the implied bi-polar phases of recessions and booms underline the need for the adoption of Keynesian demand-management policies to reduce the amplitudes and durations of growth cycles and stabilise the economy around the long-run steady-state level (Singh, 2014). An in-depth account of the switches in states and the transitional dynamics of economic growth across lower (recession) and upper (boom) regimes becomes essentially inevitable for the formulation and assessment of appropriate macroeconomic stabilisation strategies.

Most studies examining the business cycle dynamics of economic growth to date have estimated the regime-switching models mainly for a single country; see Hamilton (1989, 1994), Hansen (1999), Granger (2001), van Dijk et al (2002), Billio and Casarin (2010) and Billio et al (2013) for the surveys on the regime-switching models. This study extends the analysis and estimates the Markov-switching model of Hamilton $(1989,1994)$ for a comprehensive set of eight OECD countries. Such an analysis based on a number of countries is essentially useful to take a comparative account of the regime-switching dynamics and assess the plausible comovements of growth cycles that could occur with approximate synchronism across countries. The remainder of the study is structured as follows. Section 2 presents the model. Section 3 discusses the empirical results. Section 4 provides some policy analytics. Section 5 sums up the conclusions. 


\section{The Model}

Consider the $\mathrm{k}^{\text {th }}$ order AR process for a given stationary sequence, $\left\{\mathrm{y}_{\mathrm{t}}: \mathrm{t} \in(1, \mathrm{~T})\right\}$, represented by

$$
\begin{aligned}
& \mathrm{y}_{\mathrm{t}}=\mu\left(\mathrm{s}_{\mathrm{t}}\right)+\sum_{\mathrm{i}=1}^{\mathrm{k}} \varphi_{\mathrm{i}}\left[\mathrm{y}_{\mathrm{t}-\mathrm{i}}-\mu\left(\mathrm{s}_{\mathrm{t}-\mathrm{i}}\right)\right]+\varepsilon_{\mathrm{t}} \\
& \mathrm{y}_{\mathrm{t}}=\mu\left(\mathrm{s}_{\mathrm{t}}\right)-\sum_{\mathrm{i}=1}^{\mathrm{k}} \varphi_{\mathrm{i}} \mu\left(\mathrm{s}_{\mathrm{t}-\mathrm{i}}\right)+\sum_{\mathrm{i}=1}^{\mathrm{k}} \varphi_{\mathrm{i}} \mathrm{y}_{\mathrm{t}-\mathrm{i}}+\varepsilon_{\mathrm{t}}
\end{aligned}
$$

The $\varepsilon_{\mathrm{t}} \sim \mathrm{N}\left(0, \sigma_{\varepsilon}^{2}\right)$ is a well-behaved Gaussian white-noise stochastic process, $\varphi_{\mathrm{i}} ; \forall \mathrm{i} \in\{1, \ldots, \mathrm{k}\}$ are the AR parameters, and $\mu\left(\mathrm{s}_{\mathrm{t}}\right)$ is the conditional mean of $\mathrm{y}_{\mathrm{t}}$ that switches across the states of expansion and contraction. Hamilton $(1989,1994)$ estimates the probabilities of switches in the mean parameters according to the states of a given process. The $s_{t} \in\{1,2, \ldots, N\}$ is an unobservable random state variable and it takes only discrete values in state space $\mathrm{N}$. The $\mathrm{s}_{\mathrm{t}}$ measures the state of business cycle and it evolves according to a latent Markov-chain with transition probabilities, $\left\{p_{i j}\right\} \forall i, j \in\{1,2, \ldots N\}$, represented by $P\left\{s_{t}=j \mid s_{t-1}=i, s_{t-2}=k, \ldots\right\}=P\left\{s_{t}=j \mid s_{t-1}=i\right\}=p_{i j}$. These probabilities, $p_{i j}$, of moving from state $\mathrm{i}$ to state $\mathrm{j}$ can be mapped in a $\mathrm{N} \times \mathrm{N}$ transition matrix as

$$
\mathrm{P}=\left[\begin{array}{lccc}
\mathrm{p}_{11} & \mathrm{p}_{21} & \ldots & \mathrm{p}_{\mathrm{N} 1} \\
\mathrm{p}_{12} & \mathrm{p}_{22} & \ldots & \mathrm{p}_{\mathrm{N} 2} \\
\cdot & \cdot & \ldots & \cdot \\
\cdot & \cdot & \ldots & \cdot \\
\cdot & \cdot & \ldots & \cdot \\
\mathrm{p}_{1 \mathrm{~N}} & \mathrm{p}_{2 \mathrm{~N}} & \ldots & \mathrm{p}_{\mathrm{NN}}
\end{array}\right]
$$

Every column of $\mathrm{P}$ in the transition matrix represented by equation (3) sums to unity so that $\mathrm{P}^{\prime} 1=1$; where 1 denotes the $\mathrm{N} \times 1$ column vector of ones. The eigenvalues of the transition matrix, $\mathrm{P}$, for any N-state hidden Markov-chain can be estimated from the solution to $\left|\mathrm{P}-\lambda \mathrm{I}_{\mathrm{N}}\right|=0$. The transition probability for $\mathrm{N}=2$ state space Markov process can be represented as

$$
P=\left[\begin{array}{ll}
p_{11} & 1-p_{22} \\
1-p_{11} & p_{22}
\end{array}\right]
$$

The $\mathrm{p}_{11}$ denotes the probability that the system remains in state one and $\left(1-\mathrm{p}_{11}\right)$ shows the probability that the system switches from state one to state two. In contrast, the $p_{22}$ measures the probability that the system remains in state two and $\left(1-\mathrm{p}_{22}\right)$ shows the probability of a 


\section{SINGH Business Cycle Dynamics}

transition from state two to state one. The two-state Markov-chain becomes reducible when $\mathrm{P}$ is upper triangle with $p_{11}=1$ and, in such case, once the process enters state one, there is no possibility of its ever reverting to state two. The eigenvalues of the two-state Markov-chain satisfy the condition

$$
\Delta=\left|\begin{array}{cc}
\mathrm{p}_{11}-\lambda & 1-\mathrm{p}_{22} \\
1-\mathrm{p}_{11} & \mathrm{p}_{22}-\lambda
\end{array}\right|=\left(\mathrm{p}_{11}-\lambda\right)\left(\mathrm{p}_{22}-\lambda\right)-\left(1-\mathrm{p}_{11}\right)\left(1-\mathrm{p}_{22}\right)=0
$$

The determinant, $\Delta$, in equation (5) can be solved to obtain the values of the roots as

$$
(\lambda-1)\left(\lambda+1-\mathrm{p}_{11}-\mathrm{p}_{22}\right)=0 ; \lambda=1 \text { and } \lambda=\mathrm{p}_{11}+\mathrm{p}_{22}-1
$$

Let the root $\lambda=1=\lambda_{1}$ and $\lambda=p_{11}+p_{22}-1=\lambda_{2}$. The $\lambda_{1}=1$ is the eigenvalue for state one and $\lambda_{2}=p_{11}+p_{22}-1$ is the eigenvalue for state two in the solution given by equation (6). The $\lambda_{2}$ would be inside the unit circle as long as $0<\mathrm{p}_{11}+\mathrm{p}_{22}<2$. The two-state chain is ergodic conditional $\mathrm{p}_{11}<1, \mathrm{p}_{22}<1$ and $\mathrm{p}_{11}+\mathrm{p}_{22}>0$. The elements of the eigenvector associated with $\lambda_{i}(i=1,2)$ and given by

$$
\pi=\left[\begin{array}{c}
\frac{\left(1-p_{22}\right)}{\left(2-p_{11}-p_{22}\right)} \\
\frac{\left(1-p_{11}\right)}{\left(2-p_{11}-p_{22}\right)}
\end{array}\right]
$$

show the unconditional probabilities of being in regimes one and two at any given date (Hamilton, 1994). The unconditional probability that the process will be in regime one, $s_{t}=1$, is given by

$$
\mathrm{P}\left\{\mathrm{s}_{\mathrm{t}}=1\right\}=\frac{1-\mathrm{p}_{22}}{2-\mathrm{p}_{11}-\mathrm{p}_{22}}
$$

and that in regime two, $s_{t}=2$, by

$$
\mathrm{P}\left\{\mathrm{s}_{\mathrm{t}}=2\right\}=\left[1-\frac{1-\mathrm{p}_{22}}{2-\mathrm{p}_{11}-\mathrm{p}_{22}}\right]=\frac{1-\mathrm{p}_{11}}{2-\mathrm{p}_{11}-\mathrm{p}_{22}}
$$

Hamilton (1994) shows that the m-period ahead transition probabilities for an ergodic twostate Markov-chain can be represented by matrix $\mathrm{P}^{\mathrm{m}}$ as 
Review of Economic Analysis 8 (2016) 47-68

$$
\begin{gathered}
\mathrm{P}^{\mathrm{m}}=\left[\begin{array}{cc}
\frac{\left(1-\mathrm{p}_{22}\right)}{\left(2-\mathrm{p}_{11}-\mathrm{p}_{22}\right)} & -1 \\
\frac{\left(1-\mathrm{p}_{11}\right)}{\left(2-\mathrm{p}_{11}-\mathrm{p}_{22}\right)} & 1
\end{array}\right] \times\left[\begin{array}{cc}
1 & 0 \\
0 & \lambda_{2}^{\mathrm{m}}
\end{array}\right] \times\left[\begin{array}{cc}
1 & 1 \\
\frac{-\left(1-\mathrm{p}_{11}\right)}{\left(2-\mathrm{p}_{11}-\mathrm{p}_{22}\right)} & \frac{\left(1-\mathrm{p}_{22}\right)}{\left(2-\mathrm{p}_{11}-\mathrm{p}_{22}\right)}
\end{array}\right] \\
\mathrm{P}^{\mathrm{m}}=\left[\begin{array}{ll}
\frac{\left(1-\mathrm{p}_{22}\right)+\lambda_{2}^{\mathrm{m}}\left(1-\mathrm{p}_{11}\right)}{\left(2-\mathrm{p}_{11}-\mathrm{p}_{22}\right)} & \frac{\left(1-\mathrm{p}_{22}\right)-\lambda_{2}^{\mathrm{m}}\left(1-\mathrm{p}_{22}\right)}{\left(2-\mathrm{p}_{11}-\mathrm{p}_{22}\right)} \\
\frac{\left(1-\mathrm{p}_{11}\right)-\lambda_{2}^{\mathrm{m}}\left(1-\mathrm{p}_{11}\right)}{\left(2-\mathrm{p}_{11}-\mathrm{p}_{22}\right)} & \frac{\left(1-\mathrm{p}_{11}\right)+\lambda_{2}^{\mathrm{m}}\left(1-\mathrm{p}_{22}\right)}{\left(2-\mathrm{p}_{11}-\mathrm{p}_{22}\right)}
\end{array}\right]
\end{gathered}
$$

If the process is currently in state one, then the probability that m periods later it will be in state two is

$$
\mathrm{P}\left\{\mathrm{s}_{\mathrm{t}+\mathrm{m}}=2 \mid \mathrm{s}_{\mathrm{t}}=1\right\}=\frac{\left(1-\mathrm{p}_{11}\right)-\lambda_{2}^{\mathrm{m}}\left(1-\mathrm{p}_{11}\right)}{\left(2-\mathrm{p}_{11}-\mathrm{p}_{22}\right)}
$$

The state variable, $\mathrm{s}_{t}$, is set such that it takes on one of the $\mathrm{z}=\{\mathrm{N}\}^{[\mathrm{k}+1]}$ different values. The $\mathrm{z}=\{\mathrm{N}\}^{[\mathrm{k}+1]}$ represent the different possible combinations for $\mathrm{s}_{\mathrm{t}}, \mathrm{s}_{\mathrm{t}-1}, \mathrm{~s}_{\mathrm{t}-2}, \ldots, \mathrm{s}_{\mathrm{t}-\mathrm{k}}$; where $\mathrm{N}$ is the number of states and $\mathrm{k}$ the AR lags. The probabilistic inference for the state of business cycle, $s_{t}$, for a single date can be obtained by summing together the joint probabilities as ${ }^{1}$

$$
\begin{array}{r}
\mathrm{P}\left\{\mathrm{s}_{\mathrm{t}}=2 \mid \mathrm{y}_{\mathrm{t}}, \mathrm{y}_{\mathrm{t}-1}, \ldots, \mathrm{y}_{\mathrm{t}-\mathrm{k}}\right\}=\sum_{\mathrm{i}_{1}=1}^{2} \sum_{\mathrm{i}_{2}=1}^{2} \sum_{\mathrm{i}_{3}=1}^{2} \sum_{\mathrm{i}_{\mathrm{k}}=1}^{2} \mathrm{P}\left\{\mathrm{s}_{\mathrm{t}}=2, \mathrm{~s}_{\mathrm{t}-1}=\mathrm{i}_{1}, \mathrm{~s}_{\mathrm{t}-2}=\mathrm{i}_{2},\right. \\
\left.\mathrm{s}_{\mathrm{t}-3}=\mathrm{i}_{3}, \ldots, \mathrm{s}_{\mathrm{t}-\mathrm{k}}=\mathrm{i}_{\mathrm{k}} \mid \mathrm{y}_{\mathrm{t}}, \mathrm{y}_{\mathrm{t}-1}, \mathrm{y}_{\mathrm{t}-2}, \mathrm{y}_{\mathrm{t}-3}, \ldots, \mathrm{y}_{\mathrm{t}-\mathrm{k}} ; \hat{\theta}\right\}
\end{array}
$$

The probability of changing regimes, at any given time, is a function of the state of business cycle and is generated by an unobserved and latent Markov-chain.

\subsection{Data}

The study uses the quarterly data on the volume indices of gross domestic product (GDP) (base: $2000=100$ ) to estimate the Markov-switching model and examine the business cycle dynamics of economic growth for a comprehensive set of eight OECD countries: Belgium (1980:1-2006:3), Canada (1957:1-2006:3), Denmark (1977:1-2006:3), France (1970:12006:3), Spain (1970:1-2006:3), Sweden (1969:1-2006:3), Switzerland (1965:1-2006:3), and the United States (1957:1-2006:3). All the data are sourced from the International Financial

\footnotetext{
${ }^{1}$ The pairs of combinations of states for two-state Markov chain are equal to $\{2\}^{[\mathrm{k}+1]}=32$ for $\mathrm{k}=4$ and $\{2\}^{[\mathrm{k}+1]}=64$ for $\mathrm{k}=5$ and so on; where $\mathrm{k}$ is the number of autoregressive lags.
} 


\section{SINGH Business Cycle Dynamics}

Statistics (online), International Monetary Fund (IMF). The effects of seasonal-adjustment and filtering on non-stationarity remain an area of inconclusive controversy. The filters used to adjust for seasonal patterns could distort the underlying properties of the data series. One way to resolve seasonality would be to explain the seasonal variations in the dependent variable such as by including seasonal dummies in the model. This, however, makes the specification and estimation of the model more complicated; see Davidson and MacKinnon (1993) for a review and discussion. An alternative view suggests that the seasonality is simply a type of noise that contaminates the economic data and, therefore, one should use the seasonally-adjusted data (Sims, 1974; Davidson and MacKinnon, 1993). Several studies have used the seasonally-adjusted data to examine the nonlinear characteristics and asymmetric dynamics of a number of economic and financial time-series (Potter, 1995; Hansen, 1996; Ghysels et al, 1996; Clements and Krolzig, 1998; Stock and Watson, 2002; van Dijk et al, 2002). This study follows these studies and uses the seasonally-adjusted data drawn from the International Financial Statistics, IMF, to estimate the Markov-switching model.

\section{Empirical Results}

\subsection{Unit Root Tests}

The unit root tests are first performed to examine the time-series properties of the univariate series. The augmented Dickey-Fuller (ADF) test (Dickey and Fuller, 1981) is performed using the model estimated with drift and no trend (Model I) as well as with drift and trend (Model II). The ADF test does not reject the null hypothesis of a unit root in log-level, but rejects the null for the rate of growth of GDP series for most countries (Table 1). The Phillips-Perron (PP) test (Phillips and Perron, 1988) cross-validates the evidence and consistently does not reject the null hypothesis of a unit root in log-level GDP for most countries. The PP test rejects the null hypothesis for the rate of growth of GDP for all the countries. The KPSS (Kwiatkowski, Phillips, Schmidt, and Shin) test (Kwiatkowski et al, 1992) reverses the null and alternative hypotheses and, thus, tests the null hypothesis of no unit and stationarity against the alternative hypothesis of a unit and non-stationarity. The KPSS test for the model with a constant and no trend rejects the null hypothesis of no unit root, while that for the model with a constant and trend provides mixed evidence for the log-level series of GDP. The KPSS test generally does not reject the null hypothesis of no unit root in the first-difference of logged GDP.

The ADF and PP tests have low power in small samples, while the KPSS test has a tendency to over-reject the null hypothesis. The asymptotically powerful DF-GLS, PT, DFGLSu and QT tests (Elliott et al, 1996; Elliott, 1999), based on generalised least squares (GLS), are performed to cross-examine the evidence and test the null hypothesis of a unit root. The results obtained from the GLS-based point optimal DF-GLS, PT, DF-GLSu and QT tests

provide mixed evidence in that these tests either reject the null hypothesis of a unit root in the 
Review of Economic Analysis 8 (2016) 47-68

Table 1: Unit Root Tests

\begin{tabular}{|c|c|c|c|c|c|c|c|}
\hline \multirow[b]{3}{*}{ Country } & \multicolumn{3}{|c|}{ Conventional Tests } & \multicolumn{4}{|c|}{ GLS-Based Point Optimal Tests } \\
\hline & \multicolumn{2}{|l|}{$\mathrm{H}_{0}$ : Unit Root } & \multirow{2}{*}{$\begin{array}{l}\mathrm{H}_{0}: \text { No } \\
\text { Unit Root } \\
\text { KPSS } \\
{[1=4]}\end{array}$} & \multicolumn{2}{|c|}{$\mathrm{H}_{0}$ : Unit Root } & \multirow[b]{2}{*}{ DF-GLSu } & \multirow[b]{2}{*}{ QT } \\
\hline & $\mathrm{ADF}$ & $\mathrm{PP}[1=4]$ & & DF-GLS & PT & & \\
\hline & \multicolumn{3}{|c|}{ Log-Level GDP Series } & \multicolumn{4}{|c|}{ De-trended Log-Level GDP Series } \\
\hline & \multicolumn{7}{|c|}{ Model I: Drift and No Trend } \\
\hline Belgium & $0.32(8)$ & -0.38 & $2.229^{*}$ & $-1.50(8)$ & $6.61 *(8)$ & $-1.70(8)$ & $8.18 *(8)$ \\
\hline Canada & $-1.80(13)$ & -1.30 & $3.967^{*}$ & $4.65^{*}(3)$ & $1080.89 *(3)$ & $-0.81(3)$ & $357.06 *(3)$ \\
\hline Denmark & $0.54(13)$ & -0.77 & $2.450^{*}$ & $2.28(4)$ & $242.15^{*}(4)$ & $-0.11(4)$ & $81.52 *(4)$ \\
\hline France & $-2.27(2)$ & $-3.08 * *$ & $2.974 *$ & $2.91(2)$ & $547.01 *(2)$ & $-1.00(2)$ & $188.11 *(2)$ \\
\hline Spain & $0.40(8)$ & -0.26 & $2.970^{*}$ & $-2.03 * *(8)$ & $2.30 *(8)$ & $-2.09(8)$ & $3.86^{*}(8)$ \\
\hline Sweden & $0.71(7)$ & -2.31 & $3.043 *$ & $-1.50(12)$ & $9.78 *(12)$ & $-1.83(12)$ & $14.22 *(12)$ \\
\hline Switzerland & $-0.97(14)$ & -1.38 & $3.310^{*}$ & $3.41 * *(4)$ & $575.37 *(4)$ & $-1.30(4)$ & $248.68 *(4)$ \\
\hline \multirow[t]{2}{*}{ United States } & $-1.76(13)$ & -0.97 & $4.028^{*}$ & $3.98 *(13)$ & $809.50 *(13)$ & $-0.70(13)$ & $281.00 *(13)$ \\
\hline & \multicolumn{7}{|c|}{ Model II: Drift and Trend } \\
\hline Belgium & $-3.22 * * *(12)$ & $-12.30 *$ & 0.098 & $-1.66(8)$ & $18.14 *(8)$ & $-2.34(8)$ & $4.45^{*}(8)$ \\
\hline Canada & $-2.66(13)$ & -1.53 & $0.732 *$ & $-1.04(1)$ & $39.33 *(1)$ & $-1.41(1)$ & $17.88 *(1)$ \\
\hline Denmark & $-3.06(13)$ & $-8.81 *$ & $0.221 *$ & $-2.53(4)$ & $8.81 *(4)$ & $-2.51(4)$ & $4.66^{*}(4)$ \\
\hline France & $-3.81 * *(2)$ & $-3.80 * *$ & $0.414 *$ & $-0.67(1)$ & $63.35 *(1)$ & $-2.01(1)$ & $19.56 *(1)$ \\
\hline Spain & $-2.05(8)$ & -1.62 & $0.340^{*}$ & $-2.09(8)$ & $7.58 *(8)$ & $-2.16(8)$ & $3.43 *(8)$ \\
\hline Sweden & $-1.91(7)$ & $-15.54^{*}$ & $0.202 * *$ & $-1.70(12)$ & $29.81 *(12)$ & $-1.77(12)$ & $10.56^{*}(12)$ \\
\hline Switzerland & $-4.55 *(13)$ & $-3.59^{* *}$ & $0.186^{* *}$ & $-1.13(3)$ & $38.04 *(3)$ & $-1.93(3)$ & $13.82 *(3)$ \\
\hline \multirow[t]{3}{*}{ United States } & $-2.73(13)$ & -2.23 & $0.484 *$ & $-2.02(1)$ & $10.69 *(1)$ & $-2.37(1)$ & $4.94 *(1)$ \\
\hline & \multicolumn{3}{|c|}{ Rate of Growth of GDP Series } & \multicolumn{4}{|c|}{ First-Differenced De-trended Log-Level GDP Series } \\
\hline & \multicolumn{7}{|c|}{ Model I: Drift and No Trend } \\
\hline Belgium & $-3.78 *(7)$ & $-46.09 *$ & 0.035 & $-1.30(7)$ & $144.64 *(7)$ & $-3.52 *(7)$ & $16.40 *(7)$ \\
\hline Canada & $-6.57 *(2)$ & $-12.50 *$ & 0.259 & $-1.54(2)$ & $7.98 *(2)$ & $-3.27 *(2)$ & $3.11(2)$ \\
\hline Denmark & $-18.59 *(2)$ & $-33.56^{*}$ & 0.025 & $-6.18 *(13)$ & $0.76(13)$ & $-18.63 *(13)$ & $3.55^{*}(13)$ \\
\hline France & $-5.27 *(1)$ & $-8.77 *$ & $0.604 * *$ & $-0.71(4)$ & $17.66^{*}(4)$ & $-3.53 *(4)$ & $0.39(4)$ \\
\hline Spain & $-3.47 *(7)$ & $-11.1725^{*}$ & 0.159 & $-3.49 *(7)$ & $0.91(7)$ & $-3.48 *(7)$ & $1.77(7)$ \\
\hline Sweden & $-4.49 *(6)$ & $-50.5961 *$ & 0.016 & $-0.63(11)$ & $1199.78^{*}(11)$ & $-1.37(11)$ & $1552.78 *(11)$ \\
\hline Switzerland & $-3.32 *(14)$ & $-20.74 *$ & 0.111 & $-5.15^{*}(14)$ & $0.92(14)$ & $-11.96 *(14)$ & $0.02(14)$ \\
\hline United States & $-4.62 *(14)$ & $-10.52 *$ & 0.103 & $-4.58 *(14)$ & $0.79(14)$ & $-7.35^{*}(14)$ & $0.76(14)$ \\
\hline
\end{tabular}

(continued on the next page) 
SINGH Business Cycle Dynamics

Table 1: Unit Root Tests (continued)

\begin{tabular}{|c|c|c|c|c|c|c|c|}
\hline \multirow[b]{3}{*}{ Belgium } & \multicolumn{3}{|c|}{ Rate of Growth of GDP Series } & \multicolumn{4}{|c|}{ First-Differenced De-trended Log-Level GDP Series } \\
\hline & \multicolumn{7}{|c|}{ Model II: Drift and Trend } \\
\hline & $-3.81 * *(7)$ & $-46.72 *$ & 0.023 & $-2.22(7)$ & $335.49 *(7)$ & $-3.25 * *(7)$ & $40.63 *(7)$ \\
\hline Canada & $-6.72 *(2)$ & $-12.60 *$ & 0.109 & $-2.32(2)$ & $15.27 *(2)$ & $-3.27 *(2)$ & $3.12 *(2)$ \\
\hline Denmark & $-18.68 *(2)$ & $-33.67 *$ & 0.025 & $-9.26^{*}(13)$ & $0.20(13)$ & $-12.48 *(13)$ & $0.23(13)$ \\
\hline France & $-5.61 *(1)$ & $-9.22 *$ & $0.151 * *$ & $-1.95(1)$ & $9.32 *(1)$ & $-2.83 *(1)$ & $0.83(1)$ \\
\hline Spain & $-3.46^{* *}(7)$ & $-11.1737 *$ & $0.160 * *$ & $-3.54 *(7)$ & $3.18(7)$ & $-3.51 * *(7)$ & $1.75(7)$ \\
\hline Sweden & $-4.57 *(6)$ & $-50.5976^{*}$ & 0.014 & $-0.05(11)$ & $2634.87 *(11)$ & $0.45(11)$ & $1627.79 *(11)$ \\
\hline Switzerland & $-3.23 *(14)$ & $-20.87^{*}$ & 0.054 & $-8.73^{*}(14)$ & $0.78(14)$ & $-11.59 *(14)$ & $0.04(14)$ \\
\hline United States & $-5.11 *(14)$ & $-10.57^{*}$ & 0.033 & $-6.08 *(14)$ & $1.82(14)$ & $-7.32 *(14)$ & $0.77(14)$ \\
\hline
\end{tabular}

Notes: (1) The rate of growth of GDP is computed as $\mathrm{g}_{\mathrm{t}}=\left[\log \left(\operatorname{GDP}_{\mathrm{t}} / \mathrm{GDP}_{\mathrm{t}-1}\right)\right] \times 100=\mathrm{y}_{\mathrm{t}} ;(2) * * *$ and $* * *$ indicate the statistical significance and implied rejection of the null hypothesis at $1 \%, 5 \%$ and $10 \%$ levels, respectively; (3) Figures in parentheses are the number of lags. (4) The truncation AR lags in ADF test are selected using the Akaike Information Criterion. The PP test is performed using the spectral estimation lag (1) windows of $1=4$ and $1=8$. Similarly, the KPSS test is performed using the lag (l) windows of $l=4$ and $l=8$ for the residual variance of the Newey and West estimator (1987). The results obtained under both the lag windows generally provided similar evidence for the null hypothesis and are, therefore, reported only for one of the lag windows $(l=4)$ for both PP and KPSS tests to conserve space; (5) The de-trending is carried out on the log-level GDP series, and the GLSbased point optimal, DF-GLS, PT, DF-GLSu and QT, tests are performed on the de-trended series in level and in first-difference. The truncation AR lags in GLS-based point optimal, DF-GLS, PT, DF-GLSu and QT, tests are determined using the Modified Akaike Information Criterion (MAIC).

de-trended series in levels or do not reject the null in the de-trended series even in firstdifference in some cases (Table 1). While the evidence remains somewhat mixed, most unit root tests point towards I(1) properties of the log-level and I(0) properties of the rate of growth, $\mathrm{g}_{\mathrm{t}}=\left[\log \left(\mathrm{GDP}_{\mathrm{t}} / \mathrm{GDP}_{\mathrm{t}-1}\right)\right] \times 100=\mathrm{y}_{\mathrm{t}}$, of GDP series. The study estimates the Markov-switching model using the rate of growth of GDP, rather than level of GDP, series.

\subsection{Optimal AR Lag Polynomials}

The optimal lag structures of the stationary linear AR(k) models are determined using the model selection criteria. The maximal lag is set at $\mathrm{k}_{\max }=\operatorname{int}\left\{12(\mathrm{~T} / 100)^{1 / 4}\right\}$ and the $\operatorname{AR}(\mathrm{k})$ models, $\left(1-\varphi_{1} \mathrm{~B}-\varphi_{2} \mathrm{~B}^{2}-\ldots-\varphi_{\mathrm{p}} \mathrm{B}^{\mathrm{k}}\right) \mathrm{y}_{\mathrm{t}}=\varepsilon_{\mathrm{t}}$, are estimated to compute the AIC and SIC values (Schwert, 1989; Ng and Perron, 2001); where B is the back-shift operator such that $B y_{t} \equiv y_{t-1}, B^{2} y_{t} \equiv y_{t-2}, \ldots, B^{k} y_{t} \equiv y_{t-k}$, and AIC denotes the Akaike Information Criterion and SIC the Schwarz Information Criterion. The lag truncations based on the minimised AIC and SIC values show wide variations across countries (Table 2). The AIC may suggest an overfitting and overparameterized model in that it may capture the adhoc and transient 
correlations among the variables. In contrast, the SIC, which is dimension-consistent, could lead to too parsimonious a model in that the residuals of a selected AR model could be autocorrelated in a cascade structure with the past lags and, as such, may not be free from serial correlation. Terasvirta (1994) suggests that the use of any model selection procedure should be accompanied by a proper test for residual autocorrelation, such as the portmanteau Ljung-Box-Q (LB-Q) test (Ljung and Box, 1978). This is important because the omitted autocorrelation may also cause rejection of the null hypothesis of linearity. The study uses the $\mathrm{LB}-\mathrm{Q}(\mathrm{M})=\mathrm{T}(\mathrm{T}+2) \sum_{\mathrm{k}=1}^{\mathrm{M}}(\mathrm{T}-\mathrm{k})^{-1} \hat{\rho}_{\mathrm{k}}^{2}(\hat{\varepsilon})$ test, and tests the null hypothesis of no serial correlation in the residuals, $\hat{\varepsilon}_{\mathrm{t}}$, of the linear AR(k) models suggested by AIC and SIC; where $\hat{\rho}_{k}$ is the empirical autocorrelation function of order $k \geq 1$. The lag structures are truncated such that the selected AR models are free from residual temporal correlation. If the null hypothesis of no serial correlation in the model suggested by SIC is not rejected, then the AR lag of order $\mathrm{k} \geq 1$ suggested by SIC is used as the optimal lag. If the null hypothesis of no serial correlation is rejected in the model suggested by SIC, but not rejected in the model suggested by AIC, then the AR lag of order $k \geq 1$ suggested by AIC is used as the optimal lag polynomial (Table 2$)^{2}$.

Table 2: Optimal Lag Polynomials of the Autoregressive Models

\begin{tabular}{lllll}
\hline Country & Kmax & AIC & SIC & LB-Q \\
\hline Belgium & 12 & 12 & 8 & 8 \\
Canada & 14 & 3 & 1 & 3 \\
Denmark & 13 & 13 & 4 & 4 \\
France & 13 & 5 & 2 & 5 \\
Spain & 13 & 8 & 3 & 3 \\
Sweden & 13 & 12 & 5 & 5 \\
Switzerland & 14 & 14 & 4 & 4 \\
United States & 14 & 13 & 4 & 4 \\
\hline
\end{tabular}

Notes: (1) kmax denotes the maximal lag structure, which is set as $\mathrm{k}_{\max }=\operatorname{int}\left\{12(\mathrm{~T} / 100)^{1 / 4}\right\}$ (Schwert, 1989; Ng and Perron, 2001); (2) The LB-Q rejects the null hypothesis of no serial correlation in the residuals of AR models at the selected lags.

\footnotetext{
${ }^{2}$ The Ljung-Box Q test is performed to test up to the $8^{\text {th }}$ order serial correlation in the residuals of the AR(k) model. The AR(k) model for which the LB-Q statistic does not reject the null hypothesis of no serial correlation (at $5 \%$ level) is selected as the best-fitting model.
} 


\section{SINGH Business Cycle Dynamics}

\subsection{Maximum-Likelihood Estimates}

The Markov-switching model, with selected $\mathrm{AR}(\mathrm{k})$ structures, is estimated using the maximum-likelihood (ML) estimator for each country. The overall degree of persistence depends on both AR parameters and transition probabilities. The transition probabilities for the states of expansion and contraction are estimated along with the AR parameters of the model. The results point towards the varying levels of AR persistence across the sample countries (Table 3 ). Most of the parameters, $\varphi_{\mathrm{i}}, \forall \mathrm{i} \in\{1,2, \ldots, \mathrm{k}\}$, are statistically significant and show strong AR persistence for Denmark, Spain, Sweden and Switzerland. In contrast, the AR parameters are generally insignificant and point towards weaker persistence in the process of economic growth for Canada and the U.S. The evidence for AR persistence for Belgium and France is mixed in that it varies across AR lags. The estimates of the average rate of economic growth per quarter are represented by $\hat{\mu}_{1}$ for state one and $\hat{\mu}_{2}$ for state two. The average rate of economic growth for state one is estimated to be 0.37 for Belgium, 0.92 for Canada, -1.03 for Denmark, 1.46 for France, 0.95 for Spain, -0.86 for Sweden, -3.39 for Switzerland and 0.99 for the U.S. The estimates of $\hat{\mu}_{2}$ suggest that the average rate of economic growth in state two is estimated higher for Belgium (2.52), Denmark (1.00), Sweden (1.05) and Switzerland (0.57), and lower for France (0.36), Spain (0.59) and the U.S. (-0.77). The $\mu_{1}=\mu_{2}=0.92$ for Canada. The $\mu_{1}$ is statistically significant at $1 \%$ level for all the sample countries. The $\mu_{2}$ is statistically (i) insignificant for Canada and Spain, (ii) on the border line of $5 \%$ critical region for the U.S. and (iii) significant at $1 \%$ level for all the remaining countries in the sample.

The transition probabilities determine the expected durations of regimes in terms of the number of quarters and draw the distinction between the states of expansion and contraction. The $\mathrm{p}_{11}$ measures the probability that the expansion will be followed by another quarter of expansion, while $\mathrm{p}_{22}$ shows the probability that the contraction will be followed by another period of contraction. The expected duration of regime one is computed as Regime- $1=1 /\left(1-p_{11}\right)$ and that of regimes two as Regime- $2=1 /\left(1-p_{22}\right)$. The results suggest that the transition probably, $\mathrm{p}_{11}$, is low for Denmark (0.29) and Sweden (0.10), moderate for Switzerland (0.42) and high for Belgium (0.93), France (0.77), Spain (0.94) and the U.S. (0.95) (Table 3). The implied duration of regime one in terms of the number of quarters is estimated to be (i) low for Denmark (1.41), Sweden (1.11) and Switzerland (1.74), (ii) moderate for France (4.26), and (iii) longer for Belgium (13.50), Spain (15.42) and the U.S. (21.21). It needs to be recognised that if one of the regimes occurs rarely in Markovswitching model, then the parameters for that regime are likely to be estimated poorly. The transition probability $\mathrm{p}_{22}$ is (i) low for Belgium (0.22), (ii) moderate for Canada (0.46), Spain 
(0.59), Sweden (0.66) and the U.S. (0.48), and (iii) high for Denmark (0.76), France (0.93) and Switzerland (0.99). These probabilities suggest that the duration of regime two is (i) short for Belgium (1.27), Canada (1.86), Spain (2.47), Sweden (2.97) and the U.S. (1.93), (ii) moderate for Denmark (4.15) and France (14.13), and (iii) longer for Switzerland (72.86) ${ }^{3}$. The estimated probabilities of business cycle expansion and contraction, as a function of time, are shown in Figure 1. It follows that the sample countries differ in terms of their degrees of resilience to the economic and policy shocks.

Table 3: Maximum-Likelihood Estimates of the Markov-Switching Model

\begin{tabular}{|c|c|c|c|c|}
\hline \multirow[b]{2}{*}{ Item } & Belgium & Canada & Denmark & France \\
\hline & $\mathrm{k}=8$ & $\mathrm{k}=3$ & $\mathrm{k}=4$ & $\mathrm{k}=5$ \\
\hline & \multicolumn{4}{|l|}{ AR Parameters } \\
\hline Constant & $1.0058 *(0.00)$ & $0.6667 *(0.00)$ & $0.7166^{*}(0.00)$ & $0.2867 *(0.00)$ \\
\hline$\varphi_{1}$ & $-0.4541 *(0.00)$ & $0.1113(0.12)$ & $-0.3961 *(0.00)$ & $0.2553 *(0.00)$ \\
\hline$\varphi_{2}$ & $-0.0275(0.81)$ & $0.0331(0.64)$ & $-0.2382 *(0.01)$ & $0.2502 *(0.00)$ \\
\hline$\varphi_{3}$ & $-0.2466 * *(0.03)$ & $0.1276^{* * *}(0.07)$ & $-0.3295 *(0.00)$ & $-0.0020(0.98)$ \\
\hline$\varphi_{4}$ & $0.1645(0.15)$ & & $0.4852 *(0.00)$ & $-0.1259(0.15)$ \\
\hline$\varphi_{5}$ & $-0.0410(0.71)$ & & & $0.1312(0.12)$ \\
\hline$\varphi_{6}$ & $-0.3433 *(0.00)$ & & & \\
\hline$\varphi_{7}$ & $-0.1465(0.20)$ & & & \\
\hline \multirow[t]{2}{*}{$\varphi_{8}$} & $0.2880 *(0.01)$ & & & \\
\hline & \multicolumn{4}{|c|}{ Regime-Switching Parameters } \\
\hline$\mu_{1}$ & $0.3659 *(0.00)$ & $0.9163 *(0.00)$ & $-1.0277 *(0.00)$ & $1.4559 *(0.00)$ \\
\hline \multirow[t]{2}{*}{$\mu_{2}$} & $2.5185 *(0.00)$ & $0.9248(0.26)$ & $0.9964 *(0.00)$ & $0.3570 *(0.00)$ \\
\hline & \multicolumn{4}{|c|}{ Transition Probabilities } \\
\hline $\mathrm{p}_{11}$ & $0.9259 *(0.00)$ & $1.0259 *(0.00)$ & $0.2898 * *(0.02)$ & $0.7651 *(0.00)$ \\
\hline \multirow[t]{2}{*}{$\mathrm{p}_{22}$} & $0.2151(0.29)$ & $0.4625 *(0.01)$ & $0.7589 *(0.00)$ & $0.9292 *(0.00)$ \\
\hline & \multicolumn{4}{|c|}{ Persistence of Regimes } \\
\hline Regime-1 & 13.50 & -38.61 & 1.41 & 4.26 \\
\hline Regime-2 & 1.27 & 1.86 & 4.15 & 14.13 \\
\hline Sigma & $1.1088^{*}(0.00)$ & $0.9947 *(0.00)$ & $1.1604 *(0.00)$ & $0.3831 *(0.00)$ \\
\hline
\end{tabular}

(continued on the next page)

\footnotetext{
${ }^{3}$ The $p_{11}$ at 1.03 for Canada exceeds unity and, thus, do not seem to provide an appropriate description of the probability of regime-switching. This is further reinforced by the negative value $(-38.61)$ obtained for the duration of regime one for Canada.
} 


\section{SINGH Business Cycle Dynamics}

Table 3: Maximum-Likelihood Estimates of the Markov-Switching Model (continued)

\begin{tabular}{|c|c|c|c|c|}
\hline \multirow[b]{2}{*}{ Item } & Spain & Sweden & Switzerland & United States \\
\hline & $\mathrm{k}=3$ & $\mathrm{k}=5$ & $\mathrm{k}=4$ & $\mathrm{k}=4$ \\
\hline & \multicolumn{4}{|l|}{ AR Parameters } \\
\hline Constant & $0.3550 *(0.00)$ & $0.6331(0.00)$ & $0.3921 *(0.01)$ & $0.6054 *(0.00)$ \\
\hline$\varphi_{1}$ & $0.0015(0.99)$ & $-0.5333 *(0.00)$ & $-0.1817 *(0.01)$ & $0.2333 *(0.00)$ \\
\hline$\varphi_{2}$ & $0.3458^{*}(0.00)$ & $-0.2943 *(0.00)$ & $-0.0468(0.48)$ & $0.1166(0.11)$ \\
\hline$\varphi_{3}$ & $0.2028 * *(0.02)$ & $-0.2965^{*}(0.00)$ & $-0.1635^{*}(0.01)$ & $-0.0584(0.42)$ \\
\hline$\varphi_{4}$ & & $0.6869 *(0.00)$ & $0.5686 *(0.00)$ & $-0.0081(0.91)$ \\
\hline$\varphi_{5}$ & & $0.2340 *(0.00)$ & & \\
\hline \multicolumn{5}{|l|}{$\varphi_{6}$} \\
\hline \multicolumn{5}{|l|}{$\varphi_{7}$} \\
\hline \multicolumn{5}{|l|}{$\varphi_{8}$} \\
\hline & \multicolumn{4}{|c|}{ Regime-Switching Parameters } \\
\hline$\mu_{1}$ & $0.9532 *(0.00)$ & $-0.8574 *(0.00)$ & $-3.3937 *(0.00)$ & $0.9920 *(0.00)$ \\
\hline \multirow[t]{2}{*}{$\mu_{2}$} & $-0.2749(0.26)$ & $1.0453 *(0.00)$ & $0.5698 *(0.00)$ & $-0.7734 * *(0.05)$ \\
\hline & \multicolumn{4}{|c|}{ Transition Probabilities } \\
\hline $\mathrm{p}_{11}$ & $0.9352 *(0.00)$ & $0.0969(0.33)$ & $0.4238(0.16)$ & $0.9529 *(0.00)$ \\
\hline \multirow[t]{2}{*}{$\mathrm{p}_{22}$} & $0.5944 *(0.00)$ & $0.6635 *(0.00)$ & $0.9863 *(0.00)$ & $0.4807 * *(0.03)$ \\
\hline & \multicolumn{4}{|c|}{ Persistence of Regimes } \\
\hline Regime-1 & 15.42 & 1.11 & 1.74 & 21.21 \\
\hline Regime-2 & 2.47 & 2.97 & 72.86 & 1.93 \\
\hline Sigma & $0.6240 *(0.00)$ & $1.0830 *(0.00)$ & $1.3132 *(0.00)$ & $0.6928 * *(0.00)$ \\
\hline
\end{tabular}

Notes: (1) Figures in parentheses are the p values; (2) *; ** and *** indicate the statistical significance at $1 \%, 5 \%$ and $10 \%$ levels, respectively; (3) Some of the p-values are on the border line of critical region and, thus, strictly do not reject the null hypothesis at the indicated level of significance.

The stylized divergences in the degrees of persistence of lower and upper regimes across countries could be ascribed to several country-specific factors including the labour market policies, wage-setting institutions, provision of unemployment benefits, durations of entitlement periods, degrees of trade and financial openness, internationalisation of enterprises, magnitudes of domestic and foreign debts, incidence and severity of exogenous shocks, deregulation and liberalisation of financial markets, behaviour of private consumption and investment, management of inventories, and disparities in the stance and effectiveness of macroeconomic policies; see Stadler (1994) and Bergman et al (1998) for the surveys. The shocks emanating in one country, sector, or industry, could cascade across sectors and/or 
countries through a number of transmission mechanisms. The different structural policy settings could lead to different degrees of resilience across countries. The key dimensions of resilience are the abilities of the policy and institutional frameworks to (i) cushion the initial impact of shocks and to (ii) reduce the amplitude and persistence of subsequent output gap. The persistence of cyclical unemployment - termed as hysteresis by Blanchard and Summers (1986) - operates because a protracted slump in aggregate demand increases the long-term unemployment.

The slowdown in the wage adjustment process as well as in the reallocation of workers towards more productive jobs may delay the return of employment and output to their natural (initial) levels. If a recession lasts for several years, then the cyclical unemployment (especially of low-skilled workers) may eventually transform to structural unemployment.

Figure 1: Markov Switching Model and the Probabilities of Expansion
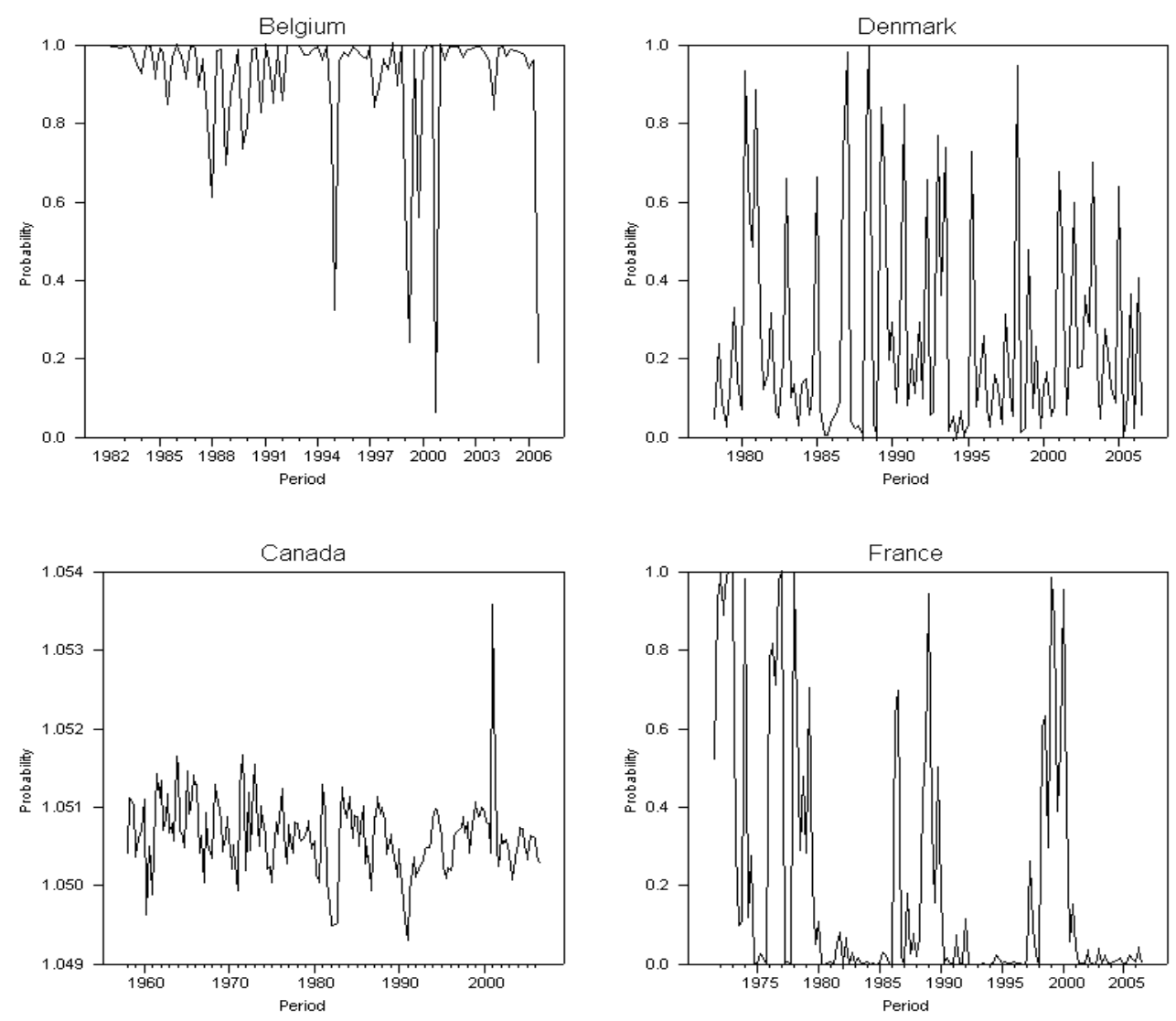

(continued on the next page) 


\section{SINGH Business Cycle Dynamics}

Figure 1: Markov Switching Model and the Probabilities of Expansion (continued)
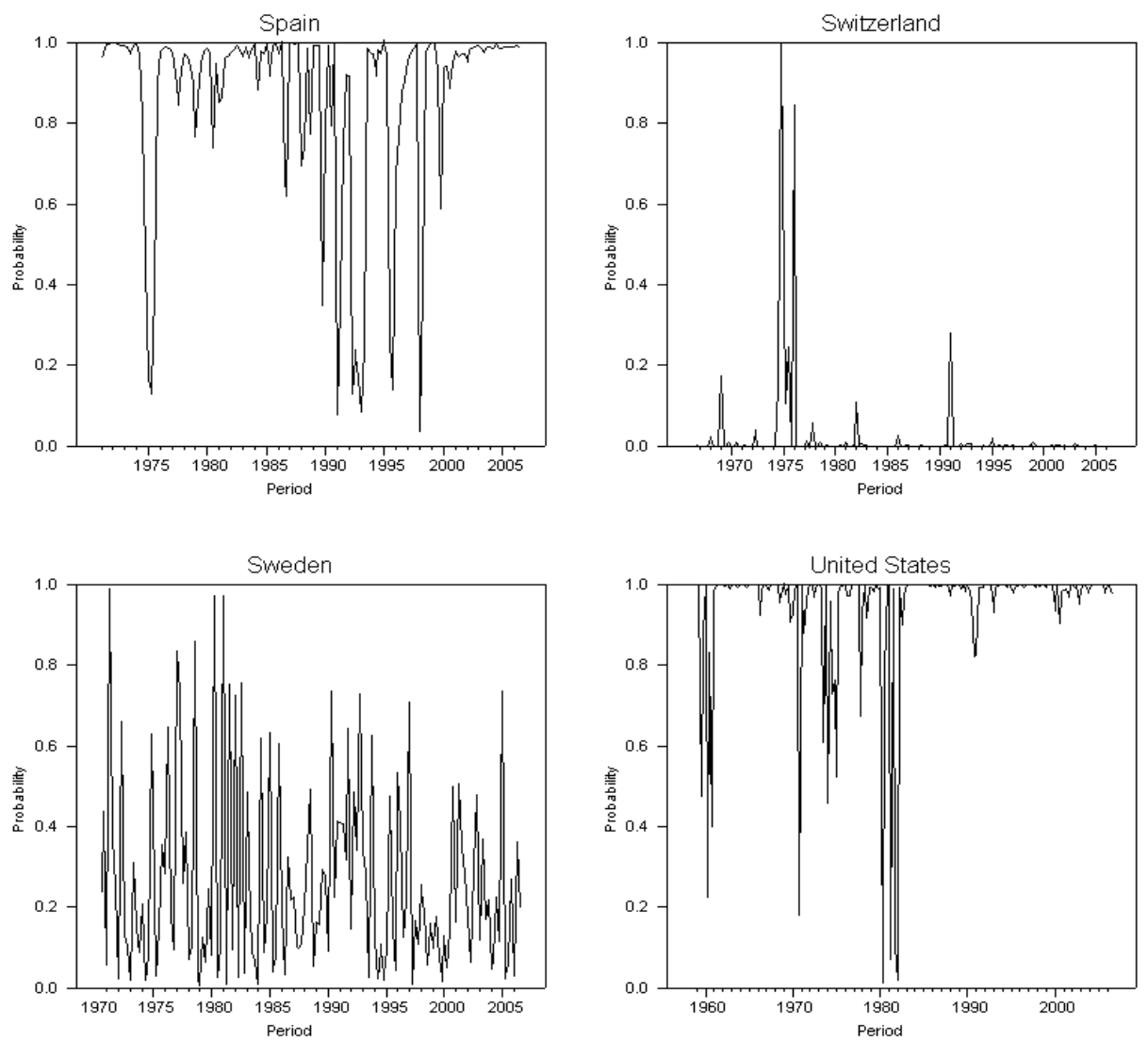

The job prospects of long-term unemployed become increasingly adverse as they (i) face human capital devaluation, (ii) become stigmatized by potential employers, and (iii) reduce their job search activity as a result of repeated setbacks (Ball, 1999). The cyclical unemployment could be caused by a slump in aggregate demand which, in turn, is closely linked to the monetary policy in that the high real interest rates depress investment and consumption (Oesch, 2010). The extended periods of weak aggregate demand - caused by high or slowly falling real interest rates - may increase not only the current unemployment, but also the equilibrium unemployment (Ball, 1999; Baccaro and Rei, 2007; Oesch, 2010). The setting of interest rates by the central banks, as such, may have long-lasting effects on the labour market (Fitoussi et al, 2000; Blanchard, 2005; Oesch, 2010). The divergences in the persistence of lower and upper regimes are accompanied by divergent macroeconomic policy requirements across countries. 


\section{Regime-Switches and Business Cycle Dynamics: Some Policy Analytics}

The switches in economic states have important implications for the formulation of macroeconomic stabilisation policies. There is a broad and general consensus across the conventional, new Classical and Keynesian schools on the effectiveness of the unanticipated policy shocks to aggregate demand and the 'plucks' in the growth of money supply. The controversy over the efficacies of the anticipated economic policies remains unresolved, however. The efficacies of the demand management monetary and fiscal policies in stabilizing the output around its long-run natural rate level and the inflation around its target level depends on several factors including the rigidities in the goods and factor markets, type of exchange rate (fixed or flexible) regime, state of business confidence, magnitudes of budget deficits and public debts, responsiveness of investment to the changes in rate of interest, and the severity of business cycle in terms of the deviation of actual output from its long-run natural rate level and that of actual inflation from its target level. The rigidities in the goods and factor (labour) markets and the hysteresis of unemployment impinge upon the recovery from recession and the acceleration of economic growth, and lead to the persistence of lower regimes. In expansionary regimes, the endogenous policy shocks to aggregate demand and the exogenous positive shocks to aggregate supply (such as productivity or technology shocks) tend to provide momentum to business booms and lead to the prolonged periods of expansion and associated inflation. The high inflation could lead to the discernible increases in inflation-linked liabilities and the dramatic declines in the assets of the firms, thereby weakening the solvency of a risk portfolio and eventually retarding the process of economic growth. The growth bubbles and economic booms, as such, could be followed by the financial crashes and economic calamities.

The economic costs in terms of both GDP losses and government expenditures incurred on the bail out of failing financial institutions (banks) during recession depend on the magnitude and duration of recession. The policy formulation needs to take into account uncertainties regarding the functioning of the economy, nature of economic shocks and/or the effects of economic policies. The autonomy of monetary policies in the euro area has been lost since the introduction of the Economic and Monetary Union in 1999. The monetary policy has since been carried out uniformly by the European Central Bank. The individual countries carry out monetary policy operations in their own markets according to the principles set by the European System of Central Banks. The fiscal policy in such case assumes a relatively significant role in responding to the country-specific shocks. It is essential to build greater safety margins in terms of the foreign exchange reserve buffers to respond to and/or safeguard against the large adverse shocks that could arise from several factors including the slowdown in export earnings and the systematic or stochastic runs on foreign exchange reserves by the international investors. The liquid assets and adequate capital buffers in the banking sector are essential to withstand the potential losses arising from the financial crises. 


\section{SINGH Business Cycle Dynamics}

The inflation during economic boom derives nominal interest rates and wage indices, and it is a risk factor for the fixed-return assets and inflation-linked liabilities. Let the rate of interest, $\tilde{i}$, denote the nominal rate of return on a composite bundle of financial assets, and let the rate of inflation, $\tilde{\pi}$, measure the rate of return on a composite bundle of physical assets. The well-known Fisher equation, $\tilde{i}=\tilde{r}+\tilde{\pi}$, can be re-arranged as $\tilde{r}=(\tilde{i}-\tilde{\pi})$, and be reinterpreted in terms of the 'relative' rate of return $(\widetilde{\mathrm{r}})$ on financial and physical assets. The 'relative' rate of return, $\tilde{\mathrm{r}}=(\tilde{\mathrm{i}}-\tilde{\pi})$, is, thus, the difference between the rate of return on financial assets measured in terms of the nominal rate of interest $(\tilde{i})$ and the rate of return on physical assets measured in terms of the rate of inflation $(\tilde{\pi})$ of the prices of such assets (Singh, 2010). The rate of return on physical assets, $\tilde{\pi}$, can be proxied in terms of the rate of increase in household capital formation deflator. The optimizing households with two-asset (financial and physical) portfolios would prefer higher acquisitions of financial assets when $\tilde{\mathrm{r}}=(\tilde{\mathrm{i}}-\tilde{\pi})>0$, physical assets when $\tilde{\mathrm{r}}=(\tilde{\mathrm{i}}-\tilde{\pi})<0$ and have a portfolio balance when $\tilde{\mathrm{r}}=(\tilde{\mathrm{i}}-\tilde{\pi})=0$. The 'relative' rates of return $(\tilde{\mathrm{r}})$ on financial assets become low or even negative in the wake of higher inflation and implied higher rates of return on physical assets ( $\tilde{\pi})$. The higher rate of inflation in the prices of physical assets and implied higher rate of return on physical assets may lead to the re-shuffling and re-balancing of the asset portfolios of households in favour of the asymmetrically higher holdings of the physical assets as compared to the financial assets. The increases in nominal rates of interest, as such, became necessary to sustain the higher rates of return on financial assets $(\tilde{i})$ as compared to the rates of return on physical assets $(\tilde{\pi})$. Such increases in nominal rates of interest could also be accompanied by the provision of saving incentives, such as tax concessions on financial saving instruments, to further augment the returns on financial assets and, thus, to induce the motivation of households for the acquisitions of these assets.

The interest rate policies directly or indirectly, through their effects on money and credit, can have a significant influence on the probabilities of occurring booms and busts (Agnello and Schuknecht, 2009). The regulatory policies that slowdown the growth of money and credit also tend to curtail the probabilities of boom. The efficacies of the counter-cyclical monetary and fiscal policies also depend on the type of exchange rate regime. The fixed exchange rate regime restricts the efficacy of monetary policy, while the flexible exchange rate system impedes the effectiveness of fiscal policy in affecting output and employment. The monetary policy tends to be more accommodative of fiscal deficits under the flexible exchange rate system. The inflation-tax collections to finance fiscal deficits are easier under the 'flexible', as compared to those under the 'fixed', exchange rate system. It is easier to resort to seigniorage and monetization of public debt in the absence of the central bank commitment to maintaining fixed exchange rate and the par-value of the domestic currency. The monetary accommodations of fiscal deficits under the flexible exchange rate regime, and the resultant rise in inflation lead to the declines in the real rates of returns on financial assets 
and, thus, to the depreciation of exchange rate. The rate of inflation becomes more persistent under the 'flexible' as compared to that under the 'fixed' exchange rate regime.

It needs to be recognised that it is illusionary to postulate that the monetary policy is completely independent even under the flexible exchange rate regime (Edwards, 2015). The Dutch Disease problem in natural-resource rich economies, causing exchange rate appreciation, reduces the competitiveness of exports and weakens the import-competing sectors. The volatility in exchange rate leads to the volatility in trade (exports and imports) and capital flows and eventually to the volatility in aggregate output and economic growth. The policy concerns for (excessive) exchange rate volatility under the purely market-driven exchange rate have effectively led to the adoption of a 'managed', rather than purely 'marketdetermined', exchange rate system. The so-called 'flexible' exchange rate is determined by both market and non-market policy forces. The exchange rate is allowed to vary within the formally and informally imposed policy bands. The large inflow of foreign capital contributes to the accumulation of foreign exchange reserves and leads to the increases in money supply and implied inflation. These increases in money supply need to be sterilized through the offsetting open market operations undertaken by the central bank in the money market. The endogenous policy needs to respond to domestic economic conditions (booms and recessions) and ensure macroeconomic stability have, thus, effectively led to the adoption of 'managed', rather than dichotomously 'fixed' or 'floating', exchange rate system. The central banks intervene in the foreign exchange market and accumulate (run down) the foreign exchange reserves to minimize the volatility in exchange rate. The sustainability or solvency constraints on the magnitudes of budget deficits and public debts relative to GDP restrict the role of fiscal policy, while the zero lower bound (nominal) interest rate limits the role of monetary policy in combating recession and reviving output and employment to their natural rate levels.

\section{Conclusions}

This study has estimated the Markov-switching model and examined the business cycle dynamics of economic growth for a comprehensive set of eight OECD countries. The probabilities of switches in economic states are computed to track the periods of recessions and expansions (booms) for the sample countries. The study finds that the estimated duration of regime one (lower regime) is (i) shorter for Denmark, Sweden and Switzerland, (ii) moderate for France, and (iii) longer for Belgium, Spain and the U.S. The persistence of regime two (upper regime) is estimated to be (i) shorter for Belgium, Canada, Spain, Sweden and the U.S., (ii) moderate for Denmark and France, and (iii) longer for Switzerland. The stylized evidence for the persistence of a given state has important implications for the Keynesian policy activism and the formulation of macroeconomic stabilisation policies. The monetary and fiscal policies are used to reduce the amplitudes and time-durations of economic growth cycles and, thus, stabilise the output around its long-run natural rate level 


\section{SINGH Business Cycle Dynamics}

and the inflation around its target level. The short-run downward rigidities in prices in the goods markets and in nominal wages in the factor (labour) market tend to impinge upon the clearance of goods and factor markets and the acceleration of economic growth during recessions, thereby leading to the pathologically longer durations of lower regimes (with negative-growth or moderate-expansions). The persistence of lower regimes necessitates the need for the adoption of expansionary monetary and fiscal policies to incite the process of economic recovery and accelerate the speed of transition towards the natural rate level of output. While the longer durations of upper regimes (with positive-growth or fast-expansions) support the use of expansionary economic policies, adequate precautions need to be taken for the inflationary implications of these policies. The growth-cycle expansions tend to be accompanied by the formation of expectations about inflation, and the higher expected inflation potentially leads to the higher actual inflation.

\section{References}

Agnello, L. and L. Schuknecht (2009), 'Booms and Busts in Housing Markets Determinants and Implications', Working Paper Series No 1071, July, European Central Bank.

Baccaro, L. and D. Rei (2007), 'Institutional Determinants of Unemployment in OECD Countries: Does the Deregulatory View Hold Water?', International Organization, July, 61(3), 527-569.

Ball, L. (1999), 'Aggregate Demand and Long-Run Unemployment', Brookings Papers on Economic Activity, No. 2, 189-236.

Bergman, U.M., M.D. Bordo, and L. Jonung (1998), 'Historical Evidence on Business Cycles: The International Experience', In Fuhrer, J.C. and S. Schuh (Eds.), 'Beyond Shocks: What Causes Business Cycles?’, Conference Series 42, June, Boston: Federal Reserve Bank of Boston.

Billio, M. and R. Casarin (2010), 'Identifying Business Cycle Turning Points with Sequential Monte Carlo Methods: An Online and Real-Time Application to the Euro Area', Journal of Forecasting, 29(1-2), January-March, 145-167.

Billio, M., L. Ferrara, D. Guégan and G.L. Mazzi (2013), 'Evaluation of Regime Switching Models for Real-Time Business Cycle Analysis of the Euro Area', Journal of Forecasting, November, 32(7), 577-586.

Blanchard, O. (2005), 'Monetary Policy and Unemployment', In Semmler, W. (Ed.), 'Monetary Policy and Unemployment: The US, Euro-area and Japan', 9-15. London: Routledge.

Blanchard, O.J. and L.H. Summers (1986), 'Hysteresis and the European Unemployment Problem', In Fischer, S. (Ed), 'NBER Macroeconomics Annual 1986', Volume 1, 15-78, National Bureau of Economic Research, The MIT Press. 
Box, G.E.P. and G.M. Jenkins (1970), 'Time Series Analysis: Forecasting and Control', San Francisco: Holden-Day.

Clements, M.P. and H.M. Krolzig (1998), 'A Comparison of the Forecast Performance of Markov-Switching and Threshold Autoregressive Models of US GNP', The Econometrics Journal, June, 1(1), 47-75.

Davidson, R. and J.G. MacKinnon (1993), 'Estimation and Inference in Econometrics', New York: Oxford University Press.

Dickey, D.A. and W.A. Fuller (1981), 'Likelihood Ratio Statistics for Autoregressive Time Series with a Unit Root', Econometrica, July, 49(4), 1057-1072.

Edwards, S. (2015), 'Monetary Policy Independence Under Flexible Exchange Rates: An Illusion?', NBER Working Paper 20893, January, National Bureau of Economic Research, Cambridge, MA.

Elliott, G. (1999), 'Efficient Tests for a Unit Root When the Initial Observation is Drawn From Its Unconditional Distribution', International Economic Review, August, 40(3), 767-784.

Elliott, G., T.J. Rothenberg and J.H. Stock (1996), 'Efficient Tests for an Autoregressive Unit Root', Econometrica, July, 64(4), 813-836.

Fitoussi, J.-P., D. Jestaz, E.S. Phelps and G. Zoega (2000), 'Roots of the Recent Recoveries: Labor Reforms or Private Sector Forces?', Brookings Papers on Economic Activity, No. 1, 237-311.

Friedman, M. (1964), 'Monetary Studies of the National Bureau', The National Bureau Enters Its $45^{\text {th }}$ Year, 44 ${ }^{\text {th }}$ Annual Report, 7-25. Reprinted in Friedman, M. (1969), 'The Optimum Quantity of Money and Other Essays', Ch.12, 261-284, Chicago: Aldine.

Friedman, M. (1993), 'The "Plucking Model” of Business Fluctuations Revisited', Economic Inquiry, April, 31(2), 171-177.

Ghysels, E., C.W.J. Granger and P.L. Siklos (1996), 'Is Seasonal Adjustment a Linear or Nonlinear Data-Filtering Process?', Journal of Business \& Economic Statistics, July, 14(3), 374-397.

Goldfeld, S.M. and R.E. Quandt (1972), 'Nonlinear Methods in Econometrics', Amsterdam: North-Holland.

Goldfeld, S.M. and R.E. Quandt (1973), 'A Markov Model for Switching Regressions', Journal of Econometrics, March, 1(1), 3-15.

Granger, C.W.J. (2001), 'Overview of Nonlinear Macroeconometric Empirical Models', Macroeconomic Dynamics, September, 5(4), 466-481.

Granger, C.W.J. and T. Terasvirta (1993), 'Modelling Nonlinear Economic Relationships', Oxford: Oxford University Press.

Hamilton, J.D. (1989), 'A New Approach to the Economic Analysis of Nonstationary Time Series and the Business Cycle’, Econometrica, March, 57(2), 357-384. 


\section{SINGH Business Cycle Dynamics}

Hamilton, J.D. (1994), 'Time Series Analysis', Princeton: Princeton University Press.

Hansen, B.E. (1996), 'Inference When a Nuisance Parameter Is Not Identified Under the Null Hypothesis', Econometrica, March, 64(2), 413-430.

Hansen, B.E. (1999), 'Testing for Linearity', Journal of Economic Surveys, December, 13(5), 551-576.

Kwiatkowski, D., P.C.B. Phillips, P. Schmidt and Y. Shin (1992), 'Testing the Null Hypothesis of Stationarity against the alternative of a Unit Root: How Sure are we that Economic Time Series have a Unit Root?', Journal of Econometrics, October-December, 54(1-3), 159-178.

Ljung, G.M. and G.E.P. Box (1978), 'On a Measure of Lack of Fit in Time Series Models', Biometrika, August, 65(2), 297-303.

Newey, W.K. and K.D. West (1987), 'A Simple, Positive Semi-Definite, Heteroskedasticity and Autocorrelation Consistent Covariance Matrix', Econometrica, May, 55(3), 703-708.

Ng, S. and P. Perron (2001), 'Lag Length Selection and the Construction of Unit Root Tests with Good Size and Power', Econometrica, November, 69(6), 1519-1554.

Oesch, D. (2010), 'What Explains High Unemployment among Low-Skilled Workers? Evidence from 21 OECD Countries', European Journal of Industrial Relations, February, 16(1), 39-55.

Phillips, P.C.B. and P. Perron (1988), 'Testing for a Unit Root in Time Series Regression', Biometrika, June, 75(2), 335-346.

Potter, S.M. (1995), 'A Nonlinear Approach to US GNP', Journal of Applied Econometrics, April-June, 10(2), 109-125.

Quandt, R.E. (1958), 'The Estimation of the Parameters of a Linear Regression System Obeying Two Separate Regimes', Journal of the American Statistical Association, December, 53(284), 873-880.

Schwert, G.W. (1989), 'Tests for Unit Roots: A Monte Carlo Investigation', Journal of Business \& Economic Statistics, April, 7(2), 5-17.

Sims, C.A. (1974), 'Seasonality in Regression', Journal of the American Statistical Association, September, 69(347), 618-626.

Singh, T. (2010), 'Does Domestic Saving Cause Economic Growth? A Time-Series Evidence from India', Journal of Policy Modeling, March-April, 32(2), 231-253.

Singh, T. (2014), 'On the Regime-Switching and Asymmetric Dynamics of Economic Growth in the OECD Countries', Research in Economics, June, 68(2), 169-192.

Stadler, G.W. (1994), 'Real Business Cycles', Journal of Economic Literature, December, 32(4), 1750-1783.

Stock, J.H. and M.W. Watson (2002), 'Has the Business Cycle Changed and Why?', In Gertler, M. and K. Rogoff (Eds.), 'NBER Macroeconomics Annual 2002', Volume 17, 159-218, National Bureau of Economic Research, The MIT Press. 
Terasvirta, T. (1994), 'Specification, Estimation, and Evaluation of Smooth Transition Autoregressive Models', Journal of the American Statistical Association, March, 89(425), 208-218.

Terasvirta, T. and H.M. Anderson (1992), 'Characterizing Nonlinearities in Business Cycles using Smooth Transition Autoregressive Models', Journal of Applied Econometrics, December, 7, S119-S136.

Tong, H. (1983), 'Threshold Models in Non-linear Time Series Analysis', Lecture Notes in Statistics, 21, Berlin: Springer.

Tong, H. and K.S. Lim (1980), 'Threshold Autoregression, Limit Cycles and Cyclical Data', Journal of the Royal Statistical Society, Series B, 42(3), 245-292.

van Dijk, D., T. Terasvirta and P.H. Franses (2002), 'Smooth Transition Autoregressive Models - A Survey of Recent Developments', Econometric Reviews, 21(1), 1-47.

Zarnowitz, V. (1985), 'Recent Work on Business Cycles in Historical Perspective: A Review of Theories and Evidence', Journal of Economic Literature, June, 23(2), 523-580.

Zarnowitz, V. (1991), 'What is a Business Cycle?', NBER Working Paper No. 3863, October, National Bureau of Economic Research, Cambridge, MA. 